OPEN ACCESS

Edited by:

Ming Lei,

University of Oxford, UK

Reviewed by:

Wayne Rodney Giles,

The University of Calgary, Canada

Derek Anthony Terrar,

University of Oxford, UK

${ }^{*}$ Correspondence:

Jie Liu, David G. Allen

and Yue-Kun Ju,

School of Medical Sciences (F13), University of Sydney, Anderson Stuart

Building, Eastern Ave., Sydney, NSW

2006, Australia

liujie@physiol.usyd.edu.au;

david.allen@sydney.edu.au;

yue-kun.ju@sydney.edu.au

Specialty section:

This article was submitted to Cardiac

Electrophysiology, a section of the journal Frontiers in Physiology

Received: 20 November 2014 Accepted: 19 February 2015 Published: 09 March 2015

Citation:

Liu J, Xin L, Benson VL, Allen DG and Ju Y-K (2015) Store-operated calcium entry and the localization of STIM1 and Orai1 proteins in isolated mouse sinoatrial node cells. Front. Physiol. 6:69

doi: 10.3389/fphys.2015.00069

\section{Store-operated calcium entry and the localization of STIM1 and Orai1 proteins in isolated mouse sinoatrial node cells}

\author{
Jie Liu ${ }^{1 *}$, Li Xin ${ }^{2}$, Victoria L. Benson ${ }^{1}$, David G. Allen ${ }^{1 *}$ and Yue-Kun Ju ${ }^{1 *}$ \\ ${ }^{1}$ School of Medical Sciences and Bosch Institute, University of Sydney, Sydney, NSW, Australia, ${ }^{2}$ Victor Chang Cardiac \\ Research Institute, Sydney, NSW, Australia
}

In many non-excitable and excitable cells, store-operated calcium entry (SOCE) represents an additional pathway for calcium entry upon $\mathrm{Ca}^{2+}$ store depletion. In a previous study, we demonstrated SOCE activity in intact mouse cardiac pacemaker tissue, specifically from sinoatrial node (SAN) tissue. However, store content as a key determinant of SOCE activity is difficult to measure in intact SAN tissue. Therefore, to investigate the interaction between SOCE and store content and its role in cardiac pacemaking, it is necessary to investigate SOCE activity in single cardiac pacemaker cells. Furthermore, recent studies in other tissues have identified two new proteins involved in SOCE, stromal interacting molecule (STIM), which is an $\mathrm{ER} \mathrm{Ca}^{2+}$ sensor, and the surface membrane channel Orai, a prototypic gene encoding for SOCE. However, whether STIM and Orai are expressed in native pacemaker cells is still unknown. In this current study, we examined SOCE activity in single firing pacemaker cells isolated from mouse sinoatrial node tissue. We found a significant rise in $\mathrm{Ca}^{2+}$ entry in response to $\mathrm{Ca}^{2+}$ store depletion. SOCE blockers reduced the amplitude and frequency of spontaneous $\mathrm{Ca}^{2+}$ transients and reduced $\mathrm{Ca}^{2+}$ store content. We demonstrated for the first time that STIM and Orai are expressed in pacemaker cells. After store depletion, STIM1 redistributed to the cell periphery and showed increased co-localization with surface membrane located Orai1, indicating a possible involvement of these proteins in SOCE activity in native cardiac pacemaker cells. These results suggest the novel concept that SOCE plays a functional role in regulating intracellular $\mathrm{Ca}^{2+}$ of cardiac pacemaker cells.

Keywords: store-operated $\mathrm{Ca}^{2+}$ entry, STIM1, Orai1, sinoatrial node

\section{Introduction}

Cardiac contraction originates in the spontaneous firing of pacemaker cells in the sinoatrial node (SAN) of the heart. Originally it was thought that the spontaneous firing of pacemaker cells was driven purely by voltage-dependent membrane currents (Noble, 1960) but subsequently it has been found that intracellular $\mathrm{Ca}^{2+}$ cycling also plays an important role (Rigg and Terrar, 1996; Ju and Allen, 1998, 1999; Rigg et al., 2000; Lakatta et al., 2010). During each spontaneous cycle, $\mathrm{Ca}^{2+}$ influx through L-type $\mathrm{Ca}^{2+}$ channels triggers sarcoplasmic reticulum (SR) 
$\mathrm{Ca}^{2+}$ release and produces a global $\mathrm{Ca}^{2+}$ transient. The loss of $\mathrm{Ca}^{2+}$ from the SR causes partial depletion which recovers as the $\mathrm{SR} \mathrm{Ca}^{2+}$ pump (SERCA) returns $\mathrm{Ca}^{2+}$ to the $\mathrm{SR}$. $\mathrm{Ca}^{2+}$ extrusion through the $\mathrm{Na}^{+} / \mathrm{Ca}^{2+}$ exchanger generates an inward current that contributes to pacemaker diastolic depolarization.(Rigg and Terrar, 1996; Ju and Allen, 1998, 2000; Rigg et al., 2000; Vinogradova et al., 2000, 2006). Although controversies still exist about the relative importance of intracellular $\mathrm{Ca}^{2+}$ cycling over membrane currents (Lakatta and DiFrancesco, 2009; Himeno et al., 2011), it is now generally accepted that pacemaker activity is orchestrated by the coupled system of membrane ionic currents (the "membrane clock") and intracellular SR calcium cycling (the “calcium clock") (for review see, Lakatta et al., 2010).

In many non-excitable and excitable cells, store-operated calcium entry (SOCE) represents an additional pathway for calcium entry into the cell to refill the SR calcium store. SOCE is activated by the decline of $\mathrm{Ca}^{2+}$ concentration within the lumen of the endoplasmic reticulum (ER) or SR. Activation of SOCE produces $\mathrm{Ca}^{2+}$ influx which provides a regulatory link between SR $\mathrm{Ca}^{2+}$ level and membrane calcium entry, thereby helping to maintain SR calcium homeostasis (Parekh and Putney, 2005). In a previous study, we demonstrated SOCE in an intact SAN tissue preparation based on a rise of intracellular $\mathrm{Ca}^{2+}\left(\left[\mathrm{Ca}^{2+}\right]_{i}\right)$ when extracellular $\mathrm{Ca}^{2+}$ was replenished after store depletion (Ju et al., 2007). However, SAN tissue contains pacemaker cells intermingled with fibroblasts, atrial myocytes and endothelium cells, all of which are capable of expressing SOCE (Camelliti et al., 2004; Chen et al., 2010; Li et al., 2011). Additionally, store content as a key determinant of SOCE activity is difficult to measure in intact SAN tissue. Therefore, to rule out possible endogenous cell contamination and investigate store content, it is necessary to investigate SOCE activity in single pacemaker cells.

In the present study, we examined SOCE in single firing pacemaker cells, by measuring the changes in intracellular $\mathrm{Ca}^{2+}$ in response to $\mathrm{SR} \mathrm{Ca}^{2+}$ store depletion. Using two different blockers of SOCE, SKF96365, and BTP-2, we estimated the contribution of SOCE to pacemaker activity and the refilling of the $\mathrm{SR} \mathrm{Ca}^{2+}$ store.

The genes encoding SOCE in pacemaker cells remain to be identified. We previously found that TRPC channel genes are expressed in pacemaker cells isolated from mouse SAN. Because the involvement of TRPC channels in SOCE has also been reported in many other cell types (Clapham, 2003; Birnbaumer, 2009), this result suggests that TRPC channels could be encoding SOCE in pacemaker cells. $\mathrm{Ca}^{2+}$ influx through TRPC channels has also been implicated in cardiac hypertrophy (Wu et al., 2010; Eder and Molkentin, 2011) and cardiac arrhythmias (Harada et al., 2012). However, despite the large numbers of reports implicating TRPCs as store-operated channels, whether activation of TRPC channels requires depletion of $\mathrm{SR} \mathrm{Ca}^{2+}$ store remain debatable (Lewis, 2007; Birnbaumer, 2009; Putney, 2009). Accumulated evidence suggests that activation of certain isoforms of TRPC channels, especially TRPC3 and TRPC6, are directly related to G-protein coupled receptor activation and phospholipase $\mathrm{C}$ mediated production of diacylglycerol, referred to as receptor-operated $\mathrm{Ca}^{2+}$ entry (ROCE) (Hofmann et al., 1999; Onohara et al., 2006; Mohl et al., 2011). Such $\mathrm{Ca}^{2+}$ entry is independent of SR store depletion.
In recent years, studies using genetic approaches have identified genes encoding the ER $\mathrm{Ca}^{2+}$ sensor, namely the stromal interaction molecule (STIM) (Liou et al., 2005; Zhang et al., 2005, also for review see Cahalan, 2009). Subsequently, the Orai family of membrane proteins was identified as forming a prototypic SOCE, the $\mathrm{Ca}^{2+}$ release activated $\mathrm{Ca}^{2+}$ channel (CRAC) (Feske et al., 2006; Vig et al., 2006; Zhang et al., 2006). CRAC channels are $\mathrm{Ca}^{2+}$-selective channels located in the cell membrane and fulfill the criteria for being store-operated (Feske et al., 2006; Vig et al., 2006). In response to decreased $\mathrm{ER} \mathrm{Ca}^{2+}$ concentration, STIM1 translocates within the ER membrane to form discrete surface membrane-associated aggregates where it activates Orai channels (Lewis, 2007; Penna et al., 2008; Wang et al., 2010b). A recent study using high resolution nuclear magnetic resonance determined the structure of protein segments from STIM1 and Orail confirmed their interaction and possible role in Orail activation (Stathopulos et al., 2013). There is now substantial evidence that SOCE plays a key role in mediating cardiomyocyte hypertrophy, both in vitro and in vivo, and there is growing support for the contribution of SOCE to $\mathrm{Ca}^{2+}$ overload associated with ischemia/reperfusion injury (Collins et al., 2013). However, the expression and cellular distribution of STIM and Orai molecules have not been determined in cardiac pacemaker cells.

In this study, we examined the expression of STIM and Orai isoforms in pacemaker cells, their cellular localization under physiological conditions, and redistribution after store depletion.

\section{Materials and Methods}

\section{Single SAN Cell Isolation}

Cardiac cells were harvested from male Balb/c mice (2-4 months old) under a protocol approved by the Animal Ethics Committee of the University of Sydney.

Single SAN cells were isolated using a modified protocol as described previously (Liu et al., 2011). Briefly, hearts were removed from animals and microdissection of the SAN region was performed with constant perfusion of Tyrode solution with $1.8 \mathrm{mmol} / \mathrm{L} \mathrm{Ca}^{2+}$ using a dissecting microscope. A strip of tissue containing the SAN region, measuring $\sim 0.5 \mathrm{~mm} \times \sim 1 \mathrm{~mm}$, was identified by anatomic landmarks and dissected out. The SAN strips were cut into 3-5 smaller strips and rinsed in a " $\mathrm{Ca}^{2+}$ free" solution containing (in mmol/L) $120 \mathrm{NaCl}, 5.4 \mathrm{KCl}$, $0.5 \mathrm{MgCl}_{2}, 1.2 \mathrm{KH}_{2} \mathrm{PO}_{4}, 20$ taurine, 11.1 glucose, 10 HEPES, 0.3 EGTA, $10 \mathrm{Na}$-Pyruvic acid, 5 Creatine, $5 \mu \mathrm{mol} / \mathrm{L}$ Blebbistatin, $2 \mathrm{mg} / \mathrm{ml}$ bovine serum albumin (BSA), $\mathrm{pH}$ 7.0. The rinsed SAN tissue strips were digested in the same " $\mathrm{Ca}^{2+}$ free" solution containing collagenase $(229 \mathrm{u} / \mathrm{ml}$, type II, Worthington Biochemical Corporation), elastase $(1.9 \mathrm{u} / \mathrm{ml})$ and protease $(0.9 \mathrm{u} / \mathrm{ml}$, type $\mathrm{XIV}$ ) for $30-40 \mathrm{~min}$ at $35 \pm 0.5^{\circ} \mathrm{C}$ and bubbled with pure oxygen. After enzyme digestion, the tissue was then washed and stored in Kruftbrühe (KB) solution which contains (in $\mathrm{mmol} / \mathrm{L}$ ), $30 \mathrm{KCl}$, $10 \mathrm{KH}_{2} \mathrm{PO}_{4}, 2 \mathrm{MgCl}_{2}, 70 \mathrm{~L}$-glutamic acid, 10 HEPES, 20 taurine, 5 creatine, 0.3 EGTA, $10 \mathrm{Na}$-Pyruvic acid, 5 Creatine, $5 \mu \mathrm{mol} / \mathrm{L}$ Blebbistatin, $80 \mathrm{KOH}, 11.1$ glucose and 10 HEPES, with $\mathrm{pH}$ adjusted to 7.2 with $\mathrm{KOH}$. Single SAN cells were released by gentle pipetting of the digested tissue strips. SAN cells were identified under light microscopy by their spindle shape and small size with 
centered single nuclei. Atrial myocytes were dissociated following the same isolation protocol while ventricular myocytes were dissociated by the collagenase-based coronary perfusion method as described elsewhere (Zhou et al., 2000). All chemicals were purchased from Sigma unless otherwise specified.

\section{Intracellular $\mathbf{C a}^{2+}$ Recording}

Isolated single mouse SAN cells were placed on laminin-coated $(20 \mu \mathrm{g} / \mathrm{ml}) 35 \mathrm{~mm}$ glass bottom petri dishes (MatTek Cultureware) for $20 \mathrm{~min}$ to attach. Fluo-4-AM (FluoroPure grade, Invitrogen. USA) was mixed with Pluronic F-127 by sonication and diluted to a final concentration of $5 \mu \mathrm{mol} / \mathrm{L}$ in Tyrode solution. This solution was used to load single pacemaker cells $(20 \mathrm{~min}$ at room temperature). After superfusion with normal Tyrode solution (with $1.8 \mathrm{mmol} / \mathrm{L} \mathrm{Ca}^{2+}$ ) for $20 \mathrm{~min}$ to de-esterify Fluo4-AM, spontaneously beating pacemaker cells were selected for study. A LSM 510 META confocal microscope (Carl Zeiss Inc., Germany) equipped with an argon laser provided excitation at $488 \mathrm{~nm}$ and the fluorescence signal was collected at wavelengths of $>515 \mathrm{~nm}$. A heated microscope stage and a $63 \times / 1.4$ oil objective heater (PeCon $\mathrm{GmbH}$, Germany) were attached to maintain cells at $37^{\circ} \mathrm{C}$ throughout the experiment. Cell shortening was recorded by line scan mode and analyzed offline with ImageJ software (NIH, USA). Intracellular $\mathrm{Ca}^{2+}$ was recorded using either line scan mode (xt mode) or frame mode (xy mode) with time series. Results were recorded at Zeiss LSM scan speed 8 ( $3.07 \mathrm{~ms} /$ line) and $10 \mathrm{~s}$ intervals exist between two consecutive frames in frame mode. Data were analyzed with Zeiss LSM image examiner (version 4.2, Carl Zeiss Inc., Germany) and imageJ (NIH, USA). Global intracellular $\mathrm{Ca}^{2+}$ levels were translated into relative fluorescence levels, F/F0, where F and F0 represent the fluorescence intensities at a given time and at minimum resting level, respectively. Maximum change in $\mathrm{F} / \mathrm{F}_{0}$ (in frame mode) was calculated as the change in the peak value after $\mathrm{Ca}^{2+}$ re-admission relative to initial level before $\mathrm{Ca}^{2+}$ removal.

\section{Reverse Trascriptase-Polymerase Chain Reaction (RT-PCR) Analysis}

Total mRNA from isolated cardiac myocytes (SAN cells, atrial and ventricular myocytes) and spleen cells were extracted with TRIzol (Invitrogen. USA) following manufacturer's protocol. Reverse transcription was carried out with $1 \mu \mathrm{g}$ total RNA using the Superscript First-Strand Synthesis System for RT-PCR (Invitrogen), according to the manufacturer's instructions. RT-PCR was performed with Platinum Taq (Invitrogen) under the following conditions as described by Wissenbach et al. (2007): one cycle $50^{\circ} \mathrm{C} / 30 \mathrm{~min}$; one cycle $94^{\circ} \mathrm{C} / 2 \mathrm{~min} ; 40-45$ cycles $94^{\circ} \mathrm{C} / 15 \mathrm{~s}, 56^{\circ} \mathrm{C} / 30 \mathrm{~s}, 72^{\circ} \mathrm{C} / 30 \mathrm{~s}$; one cycle $72^{\circ} \mathrm{C} / 5 \mathrm{~min}$. The following primer pairs, deduced from cDNA sequences and flanking at least one intron were used: 5' GAT CGG CCA GAG TTA CTC C and 5' CGA TGC ATG CGC TCG TGG (ORAI1); 5' AA GAA GGG AGA GAC ACA CAG and $5^{\prime}$ ACT CGC TGA TGG AGT TGAG G (ORAI2); 5' GCC AGT CAG CAC TCT CTG C and 5' CCA CCA GAA CAA CTT CAG CC (ORAI3); 5' GCC ACA GCT TGG CCT GG and $5^{\prime}$ GCT CCA TCA GG CTG TGG (STIM1); 5’ TGA GGA TAC CCT GCA GTG G and 5' CAG TCT
GCA GAC TCT CTA AG (STIM2); 5' GCT CGA GAT GTC ATG AAG G and 5' GGC TGT ACT GCT TAA CCA GG (HPRT1).

\section{Immunostaining and Western Blots}

Immunostaining of single SAN cells was carried out using standard protocols as described previously (Liu et al., 2011). Briefly, isolated pacemaker cells were plated onto laminin-treated slides and allowed to settle for $30 \mathrm{~min}$ before being fixed with $2 \%$ paraformaldehyde (Sigma) for $5 \mathrm{~min}$. A subset of cells was incubated with $\mathrm{Ca}^{2+}$ free Tyrode Solution with either $5 \mu \mathrm{mol} / \mathrm{L}$ cyclopiazonic acid (CPA) or $1 \mu \mathrm{mol} / \mathrm{L}$ thapsigargin (TG) for $30 \mathrm{~min}$ at room temperature before fixation. Fixed cells were washed three times with phosphate buffer solution (PBS) over $30 \mathrm{~min}$, permeabilized by $0.1 \%$ Triton X-100 (Sigma) for $5 \mathrm{~min}$, washed three times with PBS over $30 \mathrm{~min}$, and blocked with $1 \%$ bovine serum albumin (BSA; Sigma) and $4 \%$ normal Goat serum (invitrogen, USA) in PBS for 1-2 h before application of primary antibody. Primary antibodies were diluted in 1\% BSA and $4 \%$ normal goat serum in PBS. Cells were incubated with primary antibodies at an appropriate concentration (see Table 1) at $4^{\circ} \mathrm{C}$ overnight, briefly washed in PBS and then Alexa Fluo-488 goat anti-rabbit or Alexa Fluo-561 goat anti-mouse secondary antibodies (both at 1:200 dilution, Invitrogen, USA) were applied. Cells were washed three times with PBS and then mounted with Prolong Gold mounting media with DAPI (Invitrogen, USA) and cover slips were sealed with nail polish. In negative control experiments, no primary antibody was used and no labeling was detected. Confocal images were acquired with LSM 510 META confocal microscope (Carl Zeiss Inc., Germany) and analyzed with LSM image examiner.

For Western blot, strips of SAN (restricted by Crista terminalis, atrial septum, superior and inferior vena cava), atrium (from left atrium wall) and ventricle (left ventricle free wall) were freshly dissected and snap frozen in liquid nitrogen. Spleen tissue was collected in the same way and served as positive control protein. Total protein extracts were prepared with Mammalian Cell Lysis Kit (Sigma, Cat no: MCL1) containing RIPA buffer and protease inhibitor cocktail. Tissue samples were homogenized on ice using a Polytron homogenizer (PT900 CL) and cleared by centrifugation at $12,000 \mathrm{~g}$ for $10 \mathrm{~min}$. Protein extracts were separated on $8 \%$ SDS-PAGE gel and transferred to a nitrocellulose membrane (Whatman). The membranes were immunoblotted with the appropriate antibodies (Table 1) following standard procedures published elsewhere (Nishiyama et al., 2009). Immunoblots were probed with antibodies against STIM1, STIM2, Orai1, and Orai3 but not Orai2 due to lack of Orai2 mRNA expression in cardiac cells.

\section{Drugs}

Thapsigargin (TG, $1 \mu \mathrm{mol} / \mathrm{L}$ ) and Cyclopiazonic acid (CPA, $5 \mu \mathrm{mol} / \mathrm{L}$ ) which are SR $\mathrm{Ca}^{2+}$-ATPase (SERCA) inhibitors were used to deplete store content. The imidazole compound SKF-96365 (1-[2-(4-methoxyphenyl)-2-[3-(4-methoxyphenyl) propoxy]ethyl-1H-imidazole hydrochloride) has been shown to target the STIM1-Orail pathway and inhibit SOCE in cell lines (Liou et al., 2005; Huang et al., 2006). BTP-2, a bistrifluoromethyl-pyrazole derivative, is a potent and fast-acting 
TABLE 1 | List of antibody used in the study.

\begin{tabular}{|c|c|c|c|c|c|}
\hline Antibody & Company (cat \#) & Clone & $A b$ isoform & Dilution staining & Dilution western \\
\hline ORAl1 & Sigma (08264) & NA & Rabbit & $1: 100$ & \\
\hline ORAl1 & ProSci (PM-5207) & NA & Mouse & $1: 500$ & 1:1000 \\
\hline ORAI3 & ProSci (4117) & Polyclone & Rabbit & $1: 200$ & 1:1000 \\
\hline STIM1 & BD transduction & 44/stim1 & Mouse IgG2a & $1: 100$ & $1: 1000$ \\
\hline STIM2 & ProSci (4123) & Polyclone & Rabbit & $1: 400$ & $1: 1000$ \\
\hline $\mathrm{HCN} 4$ & Abcam (ab32675) & SHG 1E5 & Rat & $1: 800$ & \\
\hline Caveolin-3 & BD transduction & 26/cav-3 & Mouse IgG1 & $1: 500$ & \\
\hline SERCA2 & Abcam (ab2861) & $2 \mathrm{~A} 7-\mathrm{A} 1$ & Mouse IgG2a & $1: 500$ & \\
\hline RyR2 & ABR (MA3-916) & C3-33 & Mouse IgG1 & $1: 200$ & \\
\hline NCX1 & Swant (R3F1) & R3F1 & Mouse lgG1 & $1: 200$ & \\
\hline
\end{tabular}

SOCE blocker in a number of immortal cell lines and immune cells (He et al., 2005; Yonetoku et al., 2008). SKF-96365 and BTP-2 (both at $10 \mu \mathrm{mol} / \mathrm{L}$ ) were used as SOCE blockers in this study. All drugs were dissolved in DMSO as stock solution stored at $-20^{\circ} \mathrm{C}$ and diluted in Tyrode solution at working concentration before applying to cells.

\section{Statistical Analysis}

Data were presented as means \pm SEM. The statistical significance of effects was evaluated by Student's $t$-test or ANOVA and a value of $P<0.05$ was considered statistically significant.

\section{Results}

\section{SOCE Activities in Single Isolated Pacemaker Cells}

To investigate whether SOCE exists in isolated single pacemaker cells, we studied the changes in $\left[\mathrm{Ca}^{2+}\right]_{i}$ in response to an intervention protocol which involves removing extracellular $\mathrm{Ca}^{2+}$ in addition to the application of SR $\mathrm{Ca}^{2+}$-ATPase (SERCA) inhibitor. We previously showed that this protocol caused activation of SOCE in intact mouse SAN tissue (Ju et al., 2007). Figure 1A shows serial confocal $\mathrm{Ca}^{2+}$ images collected from an isolated single isolated pacemaker cell undergoing the SOCE activation protocol. Under control conditions $\left(1.8 \mathrm{mM}\left[\mathrm{Ca}^{2+}\right]_{\mathrm{o}}\right)$, the cell exhibited spontaneous firing and regular $\mathrm{Ca}^{2+}$ transients Figure 1A(1) (xy plot, duration 1.5s). The cell stopped firing when the SERCA inhibitor, cyclopiazonic acid (CPA, $5 \mu \mathrm{mol} / \mathrm{L}$ ) was applied along with extracellular $\mathrm{Ca}^{2+}$ withdrawal from the solution for $5 \mathrm{~min}$, which was associated with a significantly reduced $\left[\mathrm{Ca}^{2+}\right]_{\mathrm{i}}\left[\right.$ Figure 1A(2)]. A marked global rise in $\left[\mathrm{Ca}^{2+}\right]_{\mathrm{i}}$ upon $\mathrm{Ca}^{2+}$ re-admission is demonstrated in Figure 1A(3) associated with visible cell shortening (hypercontraction). $\left[\mathrm{Ca}^{2+}\right]_{\mathrm{i}}$ rapid declined after an initial transient overshoot [Figure 1A(4)]. Spontaneous $\mathrm{Ca}^{2+}$ transients associated with pacemaker firing reappeared as $\left[\mathrm{Ca}^{2+}\right]_{i}$ gradually returned to control level after wash off of CPA [Figure 1A(5)]. Figure 1B demonstrated the time course of $\mathrm{Ca}^{2+}$ fluorescence intensity changes deduced from 60 consecutively collected $\mathrm{Ca}^{2+}$ images in response to the SOCE activation protocol. The top panel showed the timing of extracellular $\left[\mathrm{Ca}^{2+}\right]$ withdrawal and readmission. A large
$\mathrm{Ca}^{2+}$ influx reached its maximum within $30 \mathrm{~s}$ after $\mathrm{Ca}^{2+}$ readmission and lasted for 1-2 min (Figure 1B top trace). In contrast, only a small $\mathrm{Ca}^{2+}$ influx was seen in the presence of the selective SOCE blocker BTP-2 (Yonetoku et al., 2008; Singh et al., 2010) (Figure 1B bottom trace). We found that SKF-96365 has similar effect to BTP-2 in single pacemaker cells and the results were similar to that previously reported in intact SAN preparations (Ju et al., 2007). Both SOCE blockers also significantly reduced CPA or TG -induced SOCE in single pacemaker cells. In addition, $\mathrm{Ca}^{2+}$ influx was not seen upon reintroducing extracellular $\mathrm{Ca}^{2+}$ after removal of extracellular $\mathrm{Ca}^{2+}$ without using SERCA inhibitors. Figure 1C compares the amplitude of the $\left[\mathrm{Ca}^{2+}\right]_{i}$ rise upon $\mathrm{Ca}^{2+}$ re-admission relative to initial levels for each treatment. These results confirm there is significant $\mathrm{Ca}^{2+}$ influx in isolated single mouse pacemaker cells in response to a SOCE activation protocol that presumably causes store depletion.

To confirm that the large $\left[\mathrm{Ca}^{2+}\right]_{\mathrm{i}}$ rise was indeed associated with a store $\mathrm{Ca}^{2+}$ depletion, the store $\mathrm{Ca}^{2+}$ content was assessed using rapid caffeine application (Figure 2). Rapid application of caffeine causes a large and rapid rise in $\left[\mathrm{Ca}^{2+}\right]_{i}$ that has been widely used to measure SR $\mathrm{Ca}^{2+}$ content (Bers, 1987). Caffeine-induced $\mathrm{Ca}^{2+}$ transients were compared under control conditions [Figure 2A(i)], after $5 \mathrm{~min}$. of extracellular $\mathrm{Ca}^{2+}$ removal [Figure $\mathbf{2 A}$ (ii)], and after $\mathrm{Ca}^{2+}$ removal combined with SERCA inhibition by TG [Figure 2A(iii)]. Three superimposed spatially-averaged traces of caffeine-induced $\mathrm{Ca}^{2+}$ transients are shown in Figure 2B. Note that regular spontaneous $\mathrm{Ca}^{2+}$ transients were seen only in control conditions before the application of caffeine (black line, Figure 2B), but not in extracellular $\mathrm{Ca}^{2+}$ free (red line) and extracellular $\mathrm{Ca}^{2+}$ free plus thapsigargin (green line). SR Ca ${ }^{2+}$ store content indicated by caffeine induced $\mathrm{Ca}^{2+}$ transients (quantified by maximum $\Delta \mathrm{F} / \mathrm{F}_{0}$ ) showed a small but non-significant reduction after extracellular $\mathrm{Ca}^{2+}$ removal (Figure 2C, $n=4$ cells from 3 mice, $P=0.81$ ) but exhibited a large and significant fall when extracellular $\mathrm{Ca}^{2+}$ removal was combined with SERCA inhibition (Figure 2C, $n=5$ cells from 3 mice, $P<0.05$ ). These data confirm that the combination of extracellular $\mathrm{Ca}^{2+}$ removal and application of a SERCA blocker cause store depletion. The large $\mathrm{Ca}^{2+}$ influx is dependent on SR $\mathrm{Ca}^{2+}$ store content and is store-operated $\mathrm{Ca}^{2+}$ entry. 


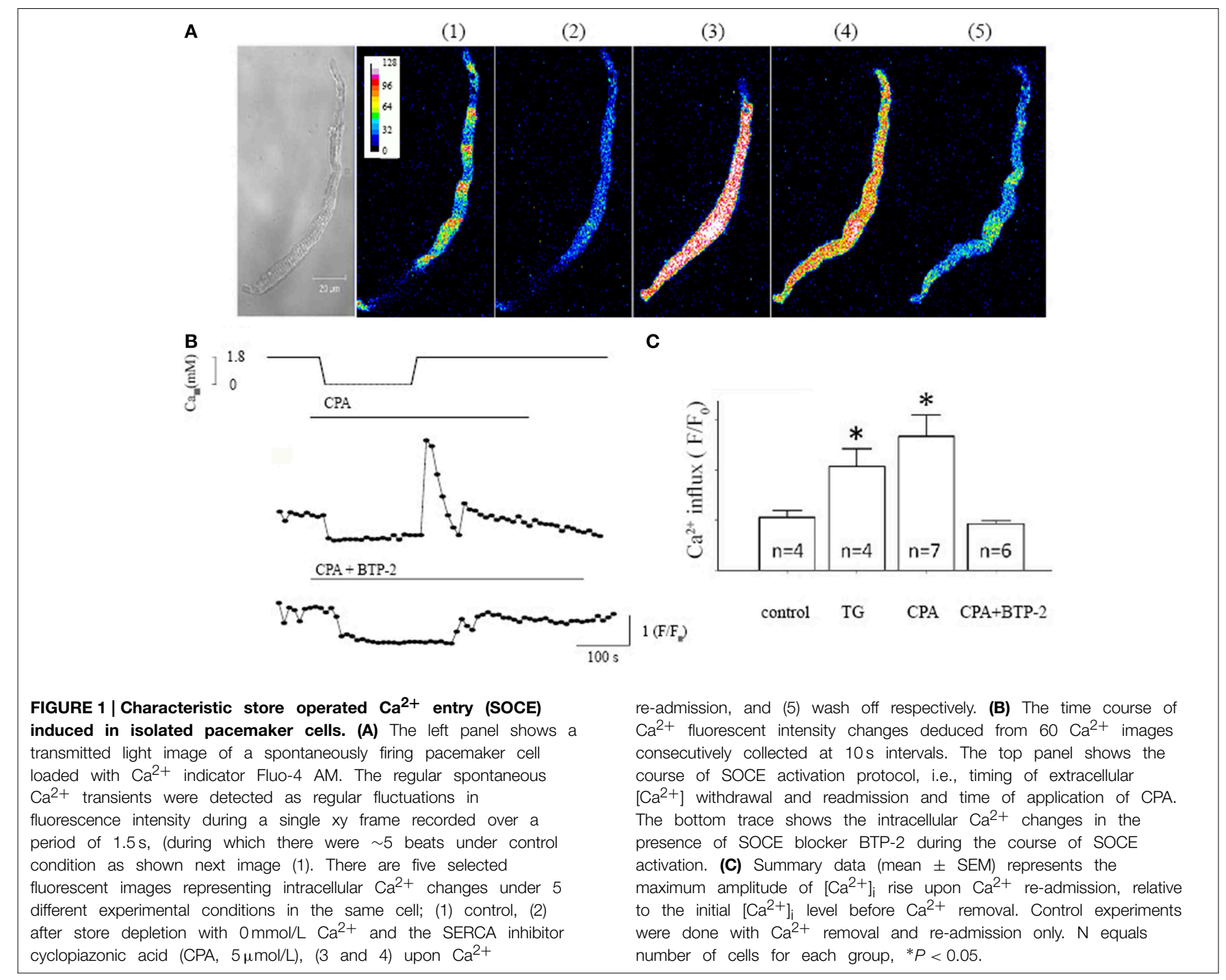

\section{SOCE Blockers Reduce Store Content}

The important physiological function of SOCE is to refill the SR $\mathrm{Ca}^{2+}$ store (Seth et al., 2012). Thus, it would be expected that SOCE blockers would cause decreased SR Ca store content.

To test this idea, we examined the effect of a SOCE blocker on $\mathrm{SR} \mathrm{Ca}^{2+}$ store content, estimated by caffeine-induced $\mathrm{Ca}^{2+}$ release (Bers, 1987). Figure 3A shows $\mathrm{Ca}^{2+}$ transients recorded from a spontaneously beating pacemaker cell. Rapid application of caffeine induced a large and rapid rise in $\left[\mathrm{Ca}^{2+}\right]_{I}$ under control conditions. BTP-2 slowed the spontaneous firing rate and reduced the amplitude of both the spontaneous $\mathrm{Ca}^{2+}$ transient and the caffeine-induced transient. Both these observations are clearly shown in Figure 3B which shows superimposed, spatially-averaged records. On average BTP-2 reduced the amplitude of the spontaneous $\mathrm{Ca}^{2+}$ transient by $24 \%(n=6$, $P=0.018$, Figure 3C). BTP-2 also reduced the amplitude of the caffeine-induced $\mathrm{Ca}^{2+}$ signal-which is indicative of $\mathrm{SR} \mathrm{Ca}^{2+}$ store content-by $22 \%(n=6$ cells from 4 mice, $P=0.026)$ (Figure 3D). These data demonstrate SOCE inhibition reduced store content and firing rate, which suggests that SOCE may participate in maintaining store content and pacemaker function. To estimate how much SOCE might be involved in normal pacemaker activity, we investigated the effect of SOCE blockers on pacemaker firing rate. When applied to normally firing pacemaker cells, BTP-2 reduced the firing rate by $16.0 \pm 1.4 \%$ ( $n=6$ cells in each group, $P<0.01$ as shown in Figure 3E). SKF-96365 also reduced pacemaker firing rate by $12.3 \pm 1.8 \%$. The negative chronotropic effects caused by inhibition of SOCE may indicate that SOCE might be involved in the regulation of pacemaker activity.

\section{Expression of STIM/Orai in Pacemaker Cells}

Although we found SOCE activity in pacemaker cells as described above, the genes encoding SOCE in pacemaker cells remain to be identified. In recent years, Orai proteins have emerged as new molecular candidates for the channels that underlie the store depletion activated $\mathrm{Ca}^{2+}$ current, I IRAC (Huang et al., 2006; Zhou et al., 2010). Before the discovery of 


\section{A}

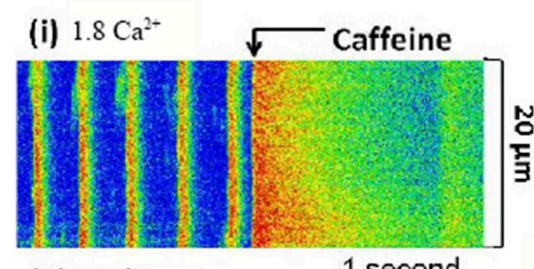

(ii) $0 \mathrm{Ca}^{2+}$

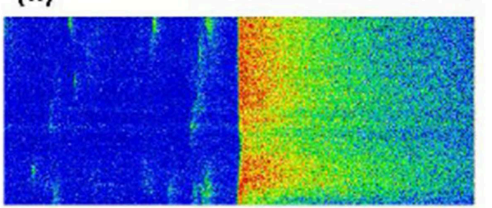

(iii) $0 \mathrm{Ca}^{2+}+\mathrm{TG}$

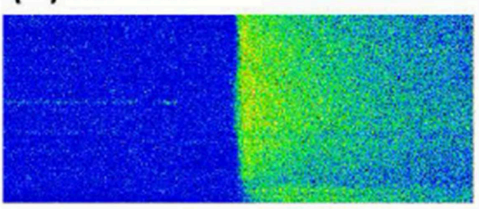

B

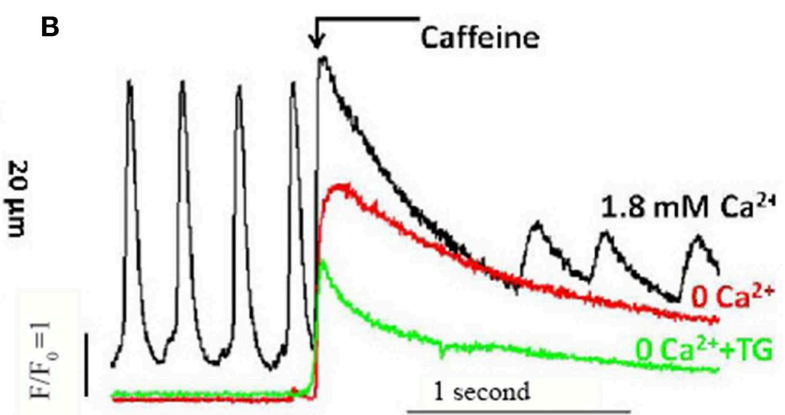

C

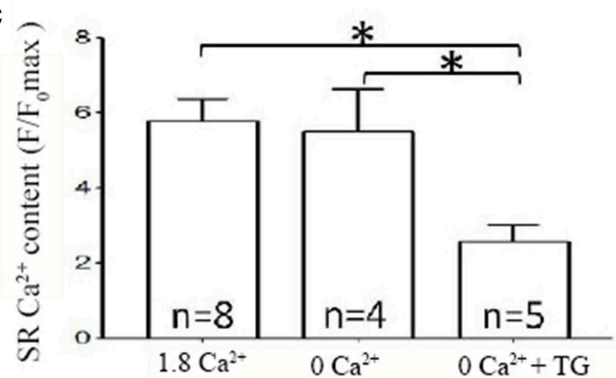

FIGURE 2 | SR $\mathrm{Ca}^{2+}$ store content measured in pacemaker cells. (A) Representative line scan recording of $\left[\mathrm{Ca}^{2+}\right]_{i}$ and caffeine induced $\mathrm{Ca}^{2+}$ transients, as the measurement of $\mathrm{SR} \mathrm{Ca}^{2+}$ store content, in SAN cells; (i) under control conditions with $1.8 \mathrm{mmol} / \mathrm{L} \mathrm{Ca}^{2+}$, (ii) with removal of external $\mathrm{Ca}^{2+}$ only and (iii) with removal of $\mathrm{Ca}^{2+}$ in the presence of TG. (B) Overlapping representative line plot traces of $\mathrm{Ca}^{2+}$ images shown in (A). The associated line colors represented $\left[\mathrm{Ca}^{2+}\right]_{\mathrm{i}}$ under control conditions (black), removal of external $\mathrm{Ca}^{2+}$ only (red) and removal of $\mathrm{Ca}^{2+}$ in the presence of TG (green), respectively. (C) Summary data (mean \pm SEM) of store content indicated by maximal rise of $F / F_{0}$ measured by caffeine induced $\mathrm{Ca}^{2}+$ release. $\mathrm{N}$ equals number of cells for each group, $* P<0.05$.
Orai genes, the TRPC channels were regarded as the most likely candidates for SOCE. We previously found that pacemaker cells express all TRPC isoforms, except TRPC5 (Ju et al., 2007). However, it is still debatable whether the activation of TRPC channels is dependent on $\mathrm{Ca}^{2+}$ depletion from $\mathrm{SR} \mathrm{Ca}^{2+}$ store (SOCE) or is dependent on G-protein coupled receptor activation (ROCE) (Hofmann et al., 1999). In addition, stromal interacting molecular 1 (STIM1) has been identified as the ER sensor. It is known that activation of SOCE requires STIM1 migration and interaction with other molecular components of SOCE (Lewis, 2007). Given the importance of STIM1 and Orai, we wanted to establish their expression in pacemaker tissue. RT-PCR was performed with mRNA extracted from isolated SAN, atrial and ventricular myocytes, respectively. Spleen tissue was used as a positive control sample, as there is abundant expression of these genes in immune cells. The housekeeping gene Hypoxanthine-Guanine Phosphoribosyltransferase (HPRT) was used as an internal control. Figure 4A shows gel images of amplified PCR products. SAN and other cardiac myocytes expressed mRNA transcripts of STIM1, STIM2, Orai1, and Orai3, but not Orai2. In contrast, spleen tissue expressed all STIM and Orai isoforms as reported by others (Wissenbach et al., 2007).

Expression of STIM and Orai proteins in SAN and other cardiac tissue were also examined by immunoblot with specific antibodies against each isoform. Figure 4B shows bands of STIM1, STIM2, Orai1, and Orai3 in cardiac tissues at their predicted molecular weight. The antibodies recognize proteins with appropriate molecular weight and confirm the expression of STIM1, STIM2, Orai1, and Orai3 in the heart tissues, including SAN, atrial and ventricular tissue. Figure 4C shows quantitative western blot analysis of STIM1 protein levels in spleen and heart with heart samples normalized to spleen.

Among the different isoforms of STIM and Orai, the STIM1 and Orail have been considered to be the most relevant components of SOCE (Lewis, 2007; Stathopulos et al., 2013). To explore the possibility that STIM1 and Orail in pacemaker cells are functioning in SOCE, we investigated the localization of STIM1 and Orail proteins in isolated SAN cells using immunohistochemistry. It is known that pacemaker cells express HCN4 (hyperpolarization-activated, cyclic nucleotide-gate cation channels, type 4) (Marionneau et al., 2005; Liu et al., 2007), a channel carrying $\mathrm{I}_{\mathrm{f}}$ current in these cells (Herrmann et al., 2007). Figure 4D shows that a HCN4 positive cell (green in color) isolated from mouse SAN tissue also demonstrates positive labeling of Orail (red in color). The distribution of Orail labeling is enhanced in the surface membrane where HCN4 is also located (yellow color showed in merged images). This result suggests that Orail could form functional channels in pacemaker cells. We found that positive HCN4 labeled cells can be also positively labeled with anti-STIM1 antibody (data not shown). STIM1 is an SR/ER $\mathrm{Ca}^{2+}$ sensor protein located predominantly within the ER/SR, but also to a limited extent in the plasma membrane (Liou et al., 2005; Wu et al., 2006). When perfused with normal $\mathrm{Ca}^{2+}$ containing solution, the distribution of STIM1 staining was 


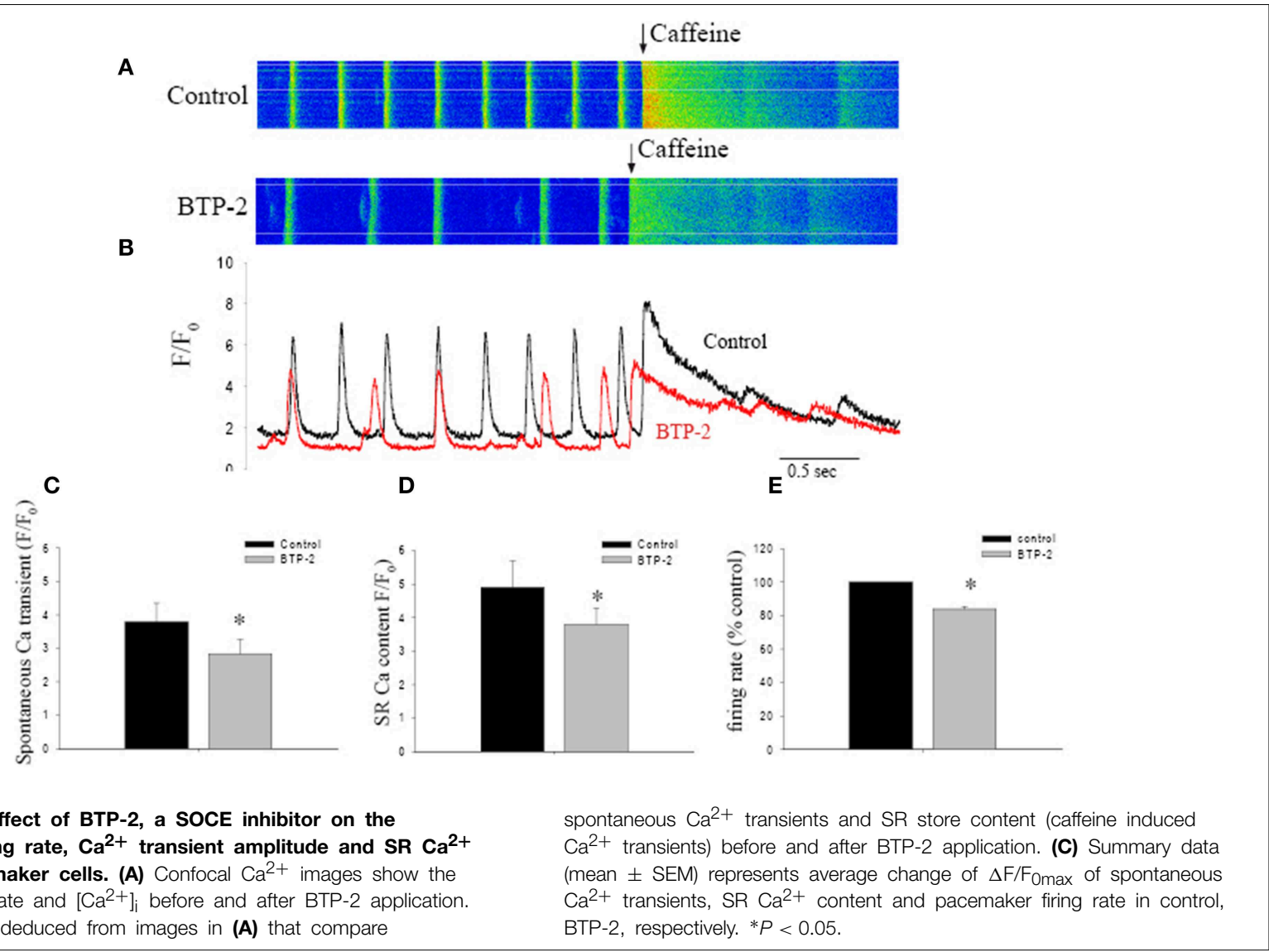

mainly intracellular as showed in two isolated SAN pacemaker cells (Figure 4E top panel). It has been reported that STIM1 can be translocated toward the plasma membrane upon SR $\mathrm{Ca}^{2+}$ store depletion in transfected RBL cells (Liou et al., 2007). After treating pacemaker cells with thapsigargin, we found that the STIM1 staining was redistributed and became predominately located at the cell membrane as shown in Figure 4E, bottom panel.

\section{Peripheral Redistribution of STIM1 upon Depletion of SR $\mathrm{Ca}^{2+}$ Store}

Store-dependent translocation of STIM1 appears to be a prerequisite for the physical interaction with Orail, which is followed by Orail activation and $\mathrm{Ca}^{2+}$ influx (Liou et al., 2007). To further investigate whether such STIM1 translocation can form a functional interaction with Orail in pacemaker cells, we examined the localization of Orail and STIM1 under control and store depleted conditions. Figure $\mathbf{5 A}$ shows a pacemaker cell that was immersed in $\mathrm{Ca}^{2+}$ free solution containing thapsigargin before labeling with Orail (red) and STIM1 (green). Orail labeling appears closer to the cell membrane, while STIM1 labeling also appears along the surface membrane where Orail is located. The colocalization of two proteins is demonstrated by the yellow staining as showed in an enlarged panel (arrows) [Figure 5A(ii)]. We examined two separate groups of pacemaker cells, the control group cells that were kept in normal Tyrode solution $\left(\mathrm{Ca}^{2+} 1.8 \mathrm{mmol} / \mathrm{L}\right)$ whereas the store depleted cells were kept in $\mathrm{Ca}^{2+}$ free solution containing the SERCA blockers CPA or TG for $30 \mathrm{~min}$. The translocation after store depletion was quantified by dividing the diameter of cells into 4 equal regions (Figure 5B) and the ratio of two outer quartiles (including cell membrane) to two inner quartiles (cell interior) was calculated (Figure 5B). For Orai1, this ratio is around 23 , indicating substantial concentration in the cell membrane, and does not change with store depletion (data not shown). Conversely for STIM1, the ratio in control cells is $1.25 \pm 0.12$ ( $n=9$ cells in $1.8 \mathrm{mM} \mathrm{Ca}^{2+}$ ), indicating very little concentration in the cell membrane, but changed significantly to $4.16 \pm 0.56(n=9$ in the presence of CPA) or $4.35 \pm 1.38$ ( $n=9$ in the presence of TG) $(P<0.05)$ when the store was depleted (Figure 5C). This data shows increased peripheral localization of STIM1 and increased colocalization of STIM1 and Orail upon store depletion. Under the same conditions, images of these antibody-stained cells were analyzed for colocalization, utilizing the colocalization coefficient (the ratio of colocalized STIM1 pixels to total STIM1 pixels). Colocalization coefficients for both STIM1 increased significantly after store depletion (Figure 5D, $n \geq 9$ cells per group, $P<0.05$ ). Similar results were obtained for the colocalization of Orail with STIM1 (not shown). This increased colocalization resulting from the peripheral redistribution of STIM1 is expected to increase the opportunity for physical interaction between STIM1 


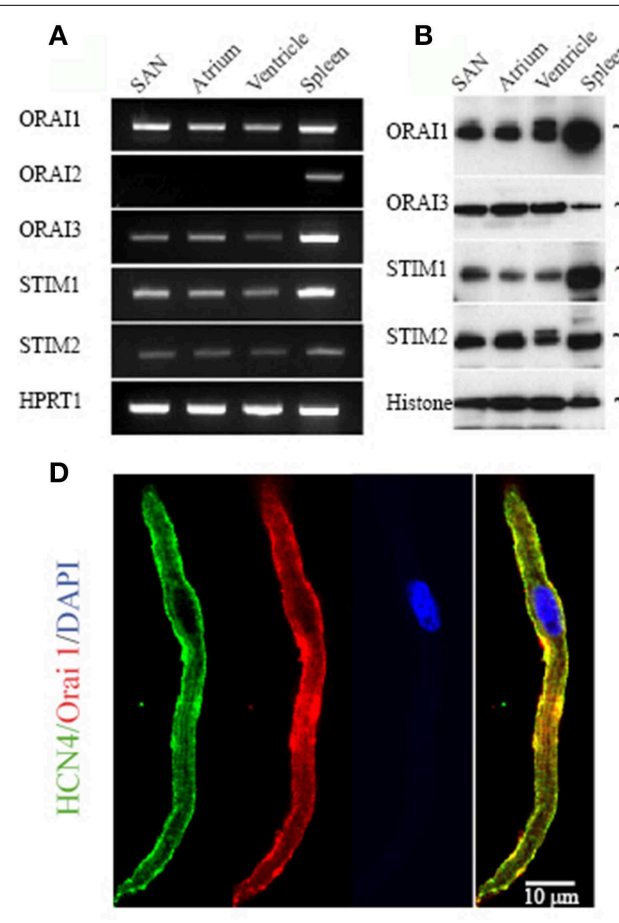

FIGURE 4 | Expression of STIM and Orai molecules in mouse cardiac myocytes. (A) Total RNA was isolated from pacemaker cells (SAN), atrial myocytes (Atrium), ventricular myocytes (Ventricle) and spleen. Transcripts of Stim1, Stim2, Orai1, Orai2, and Orai3 in cardiac myocytes were compared with the spleen as positive control. The housekeeping gene Hypoxanthine-Guanine Phosphoribosyltransferase (HPRT1) was used as an internal control. (B) Protein levels of STIM1, STIM2, Orai1, and Orai3 were examined in total protein extracts from SAN region (SAN), atrium (Atrium), ventricle (Ventricle) and spleen and determined by Western Blot analysis. The nuclear protein histone was used as loading control. (C) Bar graph showing quantitative western blot analysis of STIM1 protein levels in spleen and heart with heart samples

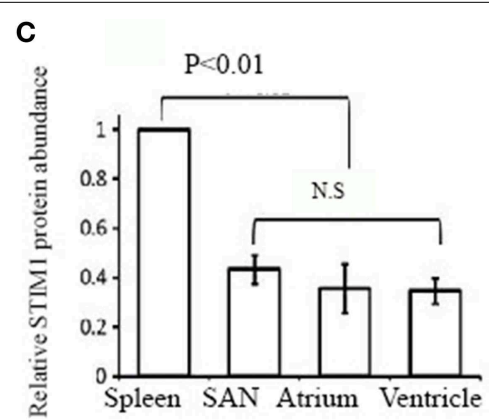

E

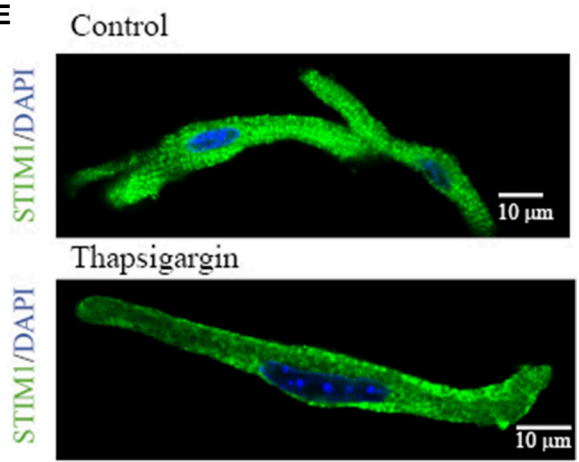

normalized to spleen as 1 ( $n=3$ gels, $P<0.05$, ANOVA). (D) Confocal images of an isolated pacemaker cell shows expression of HCN4 (green in color), a positive marker for pacemaker cells. The cell also positively stained with anti-Orai1 antibody (red in color). The nucleus is stained blue with DAPI. A merged image on the left shows the co-localization of HCN4 and Orai1 along the surface membrane (color in yellow).

(E) Representative confocal images of an isolated pacemaker cell labeled with STIM1 (green in color) and DAPI (blue in color). When perfused with normal $\mathrm{Ca}^{2+}$ containing solution, positive STIM1 staining was distributed both intracellularly and in the cell periphery as showed in the top panel. When perfused with $\mathrm{Ca}^{2+}$-free solution containing thapsigargin, STIM1 peripheral localization was enhanced, as shown in the bottom panel. and Orai1, resulting in activation of calcium influx through Orail.

\section{Discussion}

\section{SOCE and Pacemaker Function}

In the present study, we examined both the functional consequences of SOCE and molecular components of SOCE in isolated pacemaker cells. The study strengthens our earlier identification of SOCE in intact mouse SAN (Ju et al., 2007).

Given that pacemaker cells generate robust spontaneous firing by a combination of voltage-dependent channels and $\mathrm{Ca}^{2+}$ cycling, one might question what functional role SOCE can play in pacemaker cells. Application of the blockers to the normally firing pacemaker cells caused only modest reductions of the firing rate, though the fact that they were accompanied by a reduction in store level strengthens the case for the effect arising from blocking SOCE. Reduced SR store $\mathrm{Ca}^{2+}$ content would influence both diastolic and systolic SR $\mathrm{Ca}^{2+}$ release and hence influence pacemaker activity (Bassani et al., 1995; Vinogradova et al., 2004, 2006). However, we could not eliminate the possible effect of these blockers on other pacemaker currents such as voltagegated $\mathrm{Ca}^{2+}$ current or potassium currents, which might prevent us from accurately estimating the contribution of SOCE to pacemaker electrical activity.

From an evolutionary perspective, survival of an animal depends critically on the activity of several small groups of pacemaker cells. No doubt this is the reason why pacemaker cells contain several independent pacing mechanisms so that the loss of one through ingested toxin, injury or genetic mutation is not necessarily lethal. The experimental data presented here demonstrated a small change ( $\sim 15 \%$ decrease) in firing rate when SOCE was blocked, and thus supports a possible role of SOCE in regulating the firing rate under physiological conditions. Using computer simulation, we recently found that an additional inward SOCE current with a long time constant of activation (e.g., $800 \mathrm{~ms})$ could lead to a small increase $(\sim 11 \%)$ in firing rate. With such a long activation time constant, SOCE current effectively becomes a background current whose level changes little over the cardiac cycle and whose magnitude depends on the mean level of $\mathrm{Ca}^{2+}$ in the SR over the cardiac cycle, providing a calcium influx regulated by mean store size (Allen et al., 2012). 
A

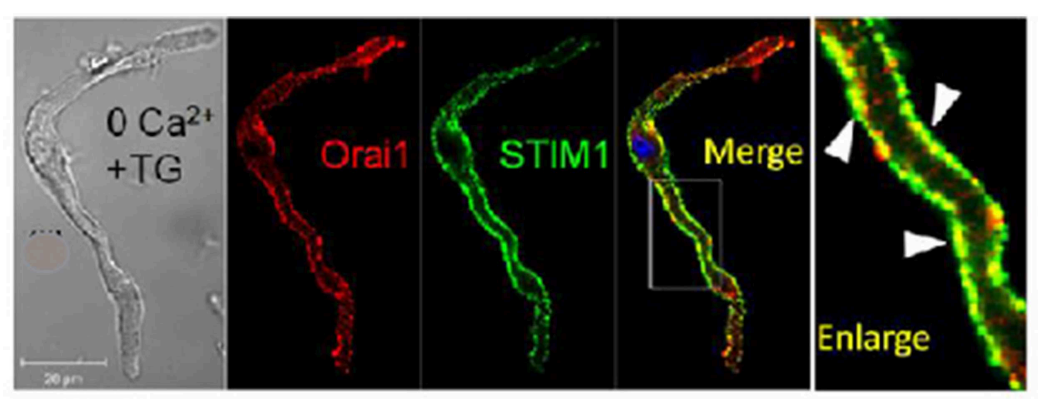

B

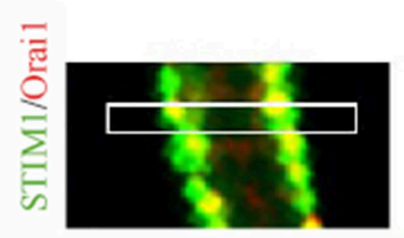

Periphery Centre Periphery

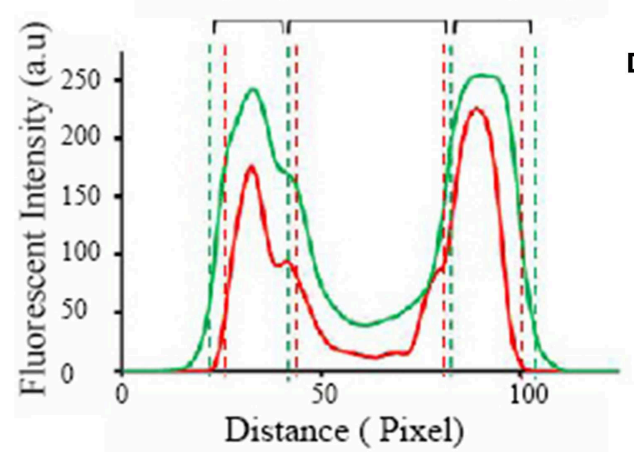

FIGURE 5 | Evidence of migration of STIM1 proteins to the cell membrane region after store depletion. $\mathrm{Ca}^{2+}$ store was depleted by treating cells with $\mathrm{Ca}^{2+}$ free solution plus $10 \mu \mathrm{mol} / \mathrm{L}$ thapsigargin. (A) The colocalization of STIM1 and Orai1 is demonstrated by membrane staining of STIM1 in the merged image (yellow in color) and is also indicated by white triangle arrows in the enlarged image (far right panel). To determine the region of a cell, the confocal image of a cell was equally divided into peripheral quarters and center quarters

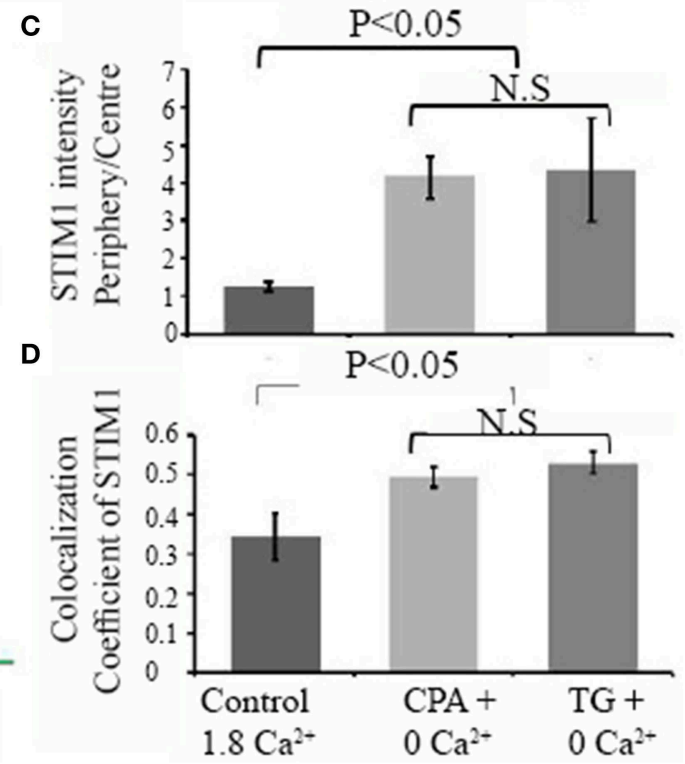

across cell width, and fluorescent intensity in each quarter was plotted against distance as demonstrated in (B). (C) Summary data of the fluorescent intensity ratio of peripheral quarters to center quarters of STIM1 under three conditions; control, CPA $+0 \mathrm{Ca}^{2+}$, thapsigargin (TG) $+0 \mathrm{Ca}^{2+}(n=9$ cells in each group, $P<0.05$, ANOVA). (D) Summary data (mean \pm SEM) of the colocalization coefficiency, a ratio of STIM1 and Orai1 colocalized pixels (Colocal) over total STIM1 pixels under three conditions. ( $n=9$ cells in each group, $P<0.05$, ANOVA).
Background currents of this sort have been previously recognized in rabbit pacemaker cells (Hagiwara et al., 1992). In this context, it would be of interest to determine whether the background current in pacemaker cells is dependent on $\mathrm{SR} \mathrm{Ca}^{2+}$ store depletion.

\section{Distribution and Localization of STIM and Orai in Pacemaker Cells}

In the present study we demonstrate that SOCE activity is present in single pacemaker cells. We also demonstrate that several new SOCE proteins, including STIM1, STIM2, Orai1, and Orai3, but not Orai2, are expressed in pacemaker cells of mouse SAN tissue. Using immunohistochemistry, we show that while Orail proteins are predominantly located in the sarcolemma, STIM1 proteins under control conditions are distributed across the cell. It has been reported that STIM activation induces conformational changes of Orai proteins and subsequent
STIM-Orai colocalization, which forms the active store-operated calcium channel (Lewis, 2007; Stathopulos et al., 2013). We also found that there was a certain proportion of STIM1 and Orai1 clustered and co-localized at the periphery of pacemaker cells in response to the store depletion. These results suggest a possible interaction between STIM1 and Orail and how they might play a functional role related to SOCE. However, to further quantify the involvement of STIM1 and Orail in SOCE activities in native pacemaker cells would require the use of tissue specific/conditional knock out related genes and proteins and then record associated changes of the amplitude of $\mathrm{Ca}^{2+}$ release activated current $\left(\mathrm{I}_{\mathrm{CRAC}}\right)$.

While the molecular mechanism of STIM1/Orail activity and their functional importance have been studied in great detail, the functional relevance of other isoforms of STIM and Orai still remain speculative (Hoth and Niemeyer, 2013). STIM2 and STIM1 share $60 \%$ homology in their amino acid sequence. 
Although we also found the presence of STIM2, the role of STIM2 in pacemaker cells might be less significant as we did not observe the translocation of STIM2 in response to store depletion (data not shown).

We also found that in addition to Orai1, Orai3 was also expressed in cardiac myocytes, including pacemaker cells, a result consistent with a recent finding in rat ventricular myocardium (Wolkowicz et al., 2011). In addition to forming functional SOCE channels, STIM1 and Orail have been shown to interact with many other $\mathrm{Ca}^{2+}$ handling proteins, including TRPC (Liao et al., 2008, 2009), the L-type Ca channel (Wang et al., 2010a), the sodium-calcium exchanger (Liu et al., 2010), the plasma membrane $\mathrm{Ca}^{2+}$ ATPase (Ritchie et al., 2012), and the sarcoplasmic reticulum $\mathrm{Ca}^{2+}$ ATPase (Lopez et al., 2008). Given that all these potential pathways could contribute to $\mathrm{Ca}^{2+}$ handling and therefore pacemaker function, these offer multiple possible directions for future research.

In our earlier work we identified that TRPC1, 3, 4, and 6 are all expressed in pacemaker cells (Ju et al., 2007). The current study demonstrates the presence of two of the best characterized SOCE components, STIM1 and Orai1, in pacemaker cells and in addition demonstrates translocation of STIM1 to the sites of Orai1

\section{References}

Allen, D. G., Ju, Y. K., Liu, J., and Imtiaz, M. (2012). "SOCE as a determinant of cardiac pacemaker function," in Store-Operated $\mathrm{Ca}^{2+}$ Entry Pathways, eds K. Groschner, W. F. Graier, and C. Romanin (Wien: Springer), 363-376.

Bassani, J. W., Yuan, W., and Bers, D. M. (1995). Fractional SR Ca release is regulated by trigger $\mathrm{Ca}$ and SR Ca content in cardiac myocytes. Am. J. Physiol. 268, C1313-C1319.

Bers, D. M. (1987). Ryanodine and the calcium content of cardiac SR assessed by caffeine and rapid cooling contractures. Am. J. Physiol. Cell Physiol. 253, C408-C415.

Birnbaumer, L. (2009). The TRPC class of ion channels: a critical review of their roles in slow, sustained increases in intracellular $\mathrm{Ca}(2+)$ concentrations. Annu. Rev. Pharmacol. Toxicol. 49, 395-426. doi: 10.1146/annurev.pharmtox.48.113006.094928

Cahalan, M. D. (2009). STIMulating store-operated $\mathrm{Ca}(2+)$ entry. Nat. Cell. Biol. 11, 669-677. doi: 10.1038/ncb0609-669

Camelliti, P., Green, C. R., LeGrice, I., and Kohl, P. (2004). Fibroblast network in rabbit sinoatrial node - structural and functional identification of homogeneous and heterogeneous cell coupling. Circ. Res. 94, 828-835. doi: 10.1161/01.RES.0000122382.19400.14

Chen, J. B., Tao, R., Sun, H. Y., Tse, H. F., Lau, C. P., and Li, G. R. (2010). Multiple $\mathrm{Ca}^{2+}$ signaling pathways regulate intracellular $\mathrm{Ca}^{2+}$ activity in human cardiac fibroblasts. J. Cell. Physiol. 223, 68-75. doi: 10.1002/jcp.22010

Clapham, D. E. (2003). TRP channels as cellular sensors. Nature 426, 517-524. doi: 10.1038 /nature02196

Collins, H. E., Zhu-Mauldin, X., Marchase, R. B., and Chatham, J. C. (2013). STIM1/Orail-mediated SOCE: current perspectives and potential roles in cardiac function and pathology. Am. J. Physiol. Heart Circ. Physiol. 305, H446-H458. doi: 10.1152/ajpheart.00104.2013

Eder, P., and Molkentin, J. D. (2011). TRPC channels as effectors of cardiac hypertrophy. Circ. Res. 108, 265-272. doi: 10.1161/CIRCRESAHA.110.225888

Feske, S., Gwack, Y., Prakriya, M., Srikanth, S., Puppel, S. H., Tanasa, B., et al. (2006). A mutation in Orail causes immune deficiency by abrogating CRAC channel function. Nature 441, 179-185. doi: 10.1038/nature04702

Hagiwara, N., Irisawa, H., Kasanuki, H., and Hosoda, S. (1992). Background current in sino-atrial node cells of the rabbit heart. J. Physiol. 448, 53-72. doi: 10.1113/jphysiol.1992.sp019029 on store depletion, as characterized in many other cell types. It has been suggested that Orai and TRPC protein form complexes that participate in $\mathrm{Ca}^{2+}$ entry with or without activation of store depletion (Liao et al., 2009). Since these SOCE related proteins are all expressed in the pacemaker cells, it is possible that SOCE or related $\mathrm{Ca}^{2+}$ signaling pathways such as receptor operated $\mathrm{Ca}^{2+}$ entry (ROCE) (Hofmann et al., 1999) might contribute to pacemaker activity under physiological or pathophysiological conditions.

\section{Limitations of the Current Study}

A patch clamp study is needed to further establish whether SOCE is accompanied by an inward current (Potier et al., 2009) which directly contributes to diastolic pacemaker potential.

\section{Acknowledgments}

This study was supported by grants from the National Health and Medical Research Council. The confocal imaging was carried out at the Bosch Institute Advanced Microscopy Facility at the University of Sydney.

Harada, M., Luo, X., Qi, X. Y., Tadevosyan, A., Maguy, A., Ordog, B., et al. (2012). Transient receptor potential canonical-3 channel-dependent fibroblast regulation in atrial fibrillation. Circulation 126, 2051-2064. doi: 10.1161/CIRCULATIONAHA.112.121830

He, L. P., Hewavitharana, T., Soboloff, J., Spassova, M. A., and Gill, D. L. (2005). A functional link between store-operated and TRPC channels revealed by the 3,5Bis(trifluoromethyl)pyrazole derivative, BTP2. J. Biol. Chem. 280, 10997-11006. doi: 10.1074/jbc.M411797200

Herrmann, S., Stieber, J., Stockl, G., Hofmann, F., and Ludwig, A. (2007). HCN4 provides a 'depolarization reserve' and is not required for heart rate acceleration in mice. EMBO J. 26, 4423-4432. doi: 10.1038/sj.emboj. 7601868

Himeno, Y., Toyoda, F., Satoh, H., Amano, A., Cha, C. Y., Matsuura, H., et al. (2011). Minor contribution of cytosolic $\mathrm{Ca}^{2+}$ transients to the pacemaker rhythm in guinea pig sinoatrial node cells. Am. J. Physiol.Heart. Circul. Physiol. 300, H251-H261. doi: 10.1152/ajpheart.00764.2010

Hofmann, T., Obukhov, A. G., Schaefer, M., Harteneck, C., Gudermann, T., and Schultz, G. (1999). Direct activation of human TRPC6 and TRPC3 channels by diacylglycerol. Nature 397, 259-263. doi: 10.1038/16711

Hoth, M., and Niemeyer, B. A. (2013). The neglected CRAC proteins: Orai2, Orai3, and STIM2. Curr. Top. Membr. 71, 237-271. doi: 10.1016/B978-0-12-4078703.00010-X

Huang, G. N., Zeng, W. Z., Kim, J. Y., Yuan, J. P., Han, L. H., Muallem, S., et al. (2006). STIM1 carboxyl-terminus activates native SOC, I-crac and TRPC1 channels. Nat. Cell Biol. 8, 1003. doi: 10.1038/ncb1454

Ju, Y. K., and Allen, D. G. (1998). Intracellular calcium and $\mathrm{Na}^{+}-\mathrm{Ca}^{2+}$ exchange current in isolated toad pacemaker cells. J. Physiol. 508, 153-166. doi: 10.1111/j.1469-7793.1998.153br.x

Ju, Y. K., and Allen, D. G. (1999). How does $\beta$-adrenergic stimulation increase heart rate? the role of intracellular $\mathrm{Ca}^{2+}$ release in amphibian pacemaker cells. J. Physiol. 516, 793-804. doi: 10.1111/j.1469-7793.1999. 0793u.x

Ju, Y. K., and Allen, D. G. (2000). The mechanisms of sarcoplasmic reticulum $\mathrm{Ca}^{2+}$ release in toad pacemaker cells. J. Physiol. 525, 695-705. doi: 10.1111/j.14697793.2000.t01-1-00695.X

Ju, Y. K., Chu, Y., Chaulet, H., Lai, D., Gervasio, O. L., Graham, R. M., et al. (2007). Store-operated $\mathrm{Ca}^{2+}$ influx and expression of TRPC genes in mouse sinoatrial node. Circ. Res. 100, 1605-1614. doi: 10.1161/CIRCRESAHA.107.152181 
Lakatta, E. G., and DiFrancesco, D. (2009). What keeps us ticking: a funny current, a calcium clock, or both? J. Mol. Cell. Cardiol. 47, 157-170. doi: 10.1016/j.yjmcc.2009.03.022

Lakatta, E. G., Maltsev, V. A., and Vinogradova, T. M. (2010). A Coupled SYSTEM of Intracellular $\mathrm{Ca}^{2+}$ clocks and surface membrane voltage clocks controls the timekeeping mechanism of the Heart's Pacemaker. Circ. Res. 106, 659-673. doi: 10.1161/CIRCRESAHA.109.206078

Lewis, R. S. (2007). The molecular choreography of a store-operated calcium channel. Nature 446, 284-287. doi: 10.1038/nature05637

Li, J., Cubbon, R. M., Wilson, L. A., Amer, M. S., McKeown, L., Hou, B., et al. (2011). Orail and CRAC channel dependence of VEGF-Activated $\mathrm{Ca}^{2+}$ entry and endothelial tube formation/novelty and significance. Circ. Res. 108, 1190-1198. doi: 10.1161/CIRCRESAHA.111.243352

Liao, Y., Erxleben, C., Abramowitz, J., Flockerzi, V., Zhu, M. X., Armstrong, D. L., et al. (2008). Functional interactions among Orail, TRPCs, and STIM1 suggest a STIM-regulated heteromeric Orai/TRPC model for SOCE/Icrac channels. Proc. Natl. Acad. Sci. U.S.A. 105, 2895-2900. doi: 10.1073/pnas.0712288105

Liao, Y., Plummer, N. W., George, M. D., Abramowitz, J., Zhu, M. X., and Birnbaumer, L. (2009). A role for Orai in TRPC-mediated Ca2+ entry suggests that a TRPC:Orai complex may mediate store and receptor operated Ca2+ entry. Proc. Natl. Acad. Sci. U.S.A. 106, 3202-3206. doi: 10.1073/pnas.0813346106

Liou, J., Fivaz, M., Inoue, T., and Meyer, T. (2007). Live-cell imaging reveals sequential oligomerization and local plasma membrane targeting of stromal interaction molecule 1 after $\mathrm{Ca}^{2+}$ store depletion. Proc. Natl. Acad. Sci. U.S.A. 104, 9301-9306. doi: 10.1073/pnas.0702866104

Liou, J., Kim, M. L., Do Heo, W., Jones, J. T., Myers, J. W., Ferrell, J., et al. (2005). STIM Is a $\mathrm{Ca}^{2+}$ sensor essential for $\mathrm{Ca}^{2+}$-store-depletion-triggered $\mathrm{Ca}^{2+}$ Influx. Curr. Biol. 15, 1235-1241. doi: 10.1016/j.cub.2005.05.055

Liu, B., Peel, S. E., Fox, J., and Hall, I. P. (2010). Reverse mode Na+/Ca2+ exchange mediated by STIM1 contributes to Ca2+ influx in airway smooth muscle following agonist stimulation. Respir. Res. 11:168. doi: 10.1186/1465-9921-11-168

Liu, J., Dobrzynski, H., Yanni, J., Boyett, M. R., and Lei, M. (2007). Organisation of the mouse sinoatrial node: structure and expression of HCN channels. Cardiovas. Res. 73, 729-738. doi: 10.1016/j.cardiores.2006.11.016

Liu, J., Sirenko, S., Juhaszova, M., Ziman, B., Shetty, V., Rain, S., et al. (2011). A full range of mouse sinoatrial node AP firing rates requires protein kinase A-dependent calcium signaling. J. Mol. Cell. Cardiol. 51, 730-739. doi: 10.1016/j.yjmcc.2011.07.028

Lopez, J. J., Jardin, I., Bobe, R., Pariente, J. A., Enouf, J., Salido, G. M., et al. (2008). STIM1 regulates acidic Ca2+ store refilling by interaction with SERCA3 in human platelets. Biochem. Pharmacol. 75, 2157-2164. doi: 10.1016/j.bcp.2008.03.010

Marionneau, C., Couette, B., Liu, J., Li, H., Mangoni, M. E., Nargeot, J., et al. (2005). Specific pattern of ionic channel gene expression associated with pacemaker activity in the mouse heart. J. Physiol. 562, 223-234. doi: 10.1113/jphysiol.2004.074047

Mohl, M. C., Iismaa, S. E., Xiao, X. H., Friedrich, O., Wagner, S., NikolovaKrstevski, V., et al. (2011). Regulation of murine cardiac contractility by activation of alpha(1A)-adrenergic receptor-operated $\mathrm{Ca}(2+)$ entry. Cardiovasc. Res. 91, 310-319. doi: 10.1093/cvr/cvr081

Nishiyama, A., Xin, L., Sharov, A. A., Thomas, M., Mowrer, G., Meyers, E., et al. (2009). Uncovering early response of gene regulatory networks in ESCs by systematic induction of transcription factors. Cell Stem Cell 5, 420-433. doi: 10.1016/j.stem.2009.07.012

Noble, D. (1960). Cardiac action and pace-maker potentials based on the HodgkinHuxley equations. Nature 188, 495-497. doi: 10.1038/188495b0

Onohara, N., Nishida, M., Inoue, R., Kobayashi, H., Sumimoto, H., Sato, Y., et al. (2006). TRPC3 and TRPC6 are essential for angiotensin II-induced cardiac hypertrophy. EMBO J. 25, 5305-5316. doi: 10.1038/sj.emboj.7601417

Parekh, A. B., and Putney, J. W. Jr. (2005). Store-operated calcium channels. Physiol. Rev. 85, 757-810. doi: 10.1152/physrev.00057.2003

Penna, A., Demuro, A., Yeromin, A. V., Zhang, S. L., Safrina, O., Parker, I., et al. (2008). The CRAC channel consists of a tetramer formed by Stim-induced dimerization of Orai dimers. Nature 456, 116-120. doi: 10.1038/nature07338

Potier, M., Gonzalez, J. C., Motiani, R. K., Abdullaev, I. F., Bisaillon, J. M., Singer, H. A., et al. (2009). Evidence for STIM1- and Orail-dependent storeoperated calcium influx through ICRAC in vascular smooth muscle cells: role in proliferation and migration. FASEB J. 23, 2425-2437. doi: 10.1096/fj.09-131128
Putney, J. W. (2009). Capacitative calcium entry: from concept to molecules. Immunol. Rev. 231, 10-22. doi: 10.1111/j.1600-065X.2009.00810.x

Rigg, L., Heath, B. M., Cui, Y., and Terrar, D. A. (2000). Localisation and functional significance of ryanodine receptors during beta-adrenoceptor stimulation in the guinea-pig sino-atrial node. Cardiovasc. Res. 48, 254-264. doi: 10.1016/S0008-6363(00)00153-X

Rigg, L., and Terrar, D. A. (1996). Possible role of calcium release from the sarcoplasmic reticulum in pacemaking in guinea-pig sino-atrial node. Exp. Physiol. 81, 877-880. doi: 10.1113/expphysiol.1996.sp003983

Ritchie, M. F., Samakai, E., and Soboloff, J. (2012). STIM1 is required for attenuation of PMCA-mediated Ca2+ clearance during T-cell activation. EMBO J. 31, 1123-1133. doi: 10.1038/emboj.2011.495

Seth, M., Li, T., Graham, V., Burch, J., Finch, E., Stiber, J. A., et al. (2012). Dynamic regulation of sarcoplasmic reticulum $\mathrm{Ca}(2+)$ stores by stromal interaction molecule 1 and sarcolipin during muscle differentiation. Dev. Dyn. 241, 639-647. doi: 10.1002/dvdy.23760

Singh, A., Hildebrand, M. E., Garcia, E., and Snutch, T. P. (2010). The transient receptor potential channel antagonist SKF96365 is a potent blocker of lowvoltage-activated T-type calcium channels. Br. J. Pharmacol. 160, 1464-1475. doi: 10.1111/j.1476-5381.2010.00786.x

Stathopulos, P. B., Schindl, R., Fahrner, M., Zheng, L., Gasmi-Seabrook, G. M., Muik, M., et al. (2013). STIM1/Orail coiled-coil interplay in the regulation of store-operated calcium entry. Nat. Commun. 4, 2963. doi: $10.1038 /$ ncomms 3963

Vig, M., Peinelt, C., Beck, A., Koomoa, D. L., Rabah, D., Koblan-Huberson, M., et al. (2006). CRACM1 is a plasma membrane protein essential for storeoperated $\mathrm{Ca}^{2+}$ entry. Science 312, 1220-1223. doi: 10.1126/science.1127883

Vinogradova, T. M., Lyashkov, A. E., Zhu, W., Ruknudin, A. M., Sirenko, S., Yang, D., et al. (2006). High basal protein kinase A-dependent phosphorylation drives rhythmic internal $\mathrm{Ca}^{2+}$ store oscillations and spontaneous beating of cardiac pacemaker cells. Circ. Res. 98, 505-514. doi: 10.1161/01.RES.0000204575.94040.d1

Vinogradova, T. M., Zhou, Y. Y., Bogdanov, K. Y., Yang, D., Kuschel, M., Cheng, H., et al. (2000). Sinoatrial node pacemaker activity requires $\mathrm{Ca}^{2+} /$ calmodulin-dependent protein kinase II activation. Circ. Res. 87, 760-767. doi: 10.1161/01.RES.87.9.760

Vinogradova, T. M., Zhou, Y. Y., Maltsev, V., Lyashkov, A., Stern, M., and Lakatta, E. G. (2004). Rhythmic ryanodine receptor $\mathrm{Ca} 2+$ releases during diastolic depolarization of sinoatrial pacemaker cells do not require membrane depolarization. Circ. Res. 94, 802-809. doi: 10.1161/01.RES.0000122045.55331.0F

Wang, Y., Deng, X., and Gill, D. L. (2010b). Calcium signaling by STIM and orai: intimate coupling details revealed. Sci. Signal. 3:e42. doi: 10.1126/scisignal.3148pe42

Wang, Y., Deng, X., Mancarella, S., Hendron, E., Eguchi, S., Soboloff, J., et al. (2010a). The calcium store sensor, STIM1, reciprocally controls Orai and CaV1.2 channels. Science 330, 105-109. doi: 10.1126/science. 1191086

Wissenbach, U., Philipp, S. E., Gross, S. A., Cavalie, A., and Flockerzi, V. (2007). Primary structure, chromosomal localization and expression in immune cells of the murine ORAI and STIM genes. Cell Calcium 42, 439-446. doi: 10.1016/j.ceca.2007.05.014

Wolkowicz, P. E., Huang, J., Umeda, P. K., Sharifov, O. F., Tabengwa, E., Halloran, B. A., et al. (2011). Pharmacological evidence for Orai channel activation as a source of cardiac abnormal automaticity. Europ. J. Pharmacol. 668, 208-216. doi: 10.1016/j.ejphar.2011.06.025

Wu, M. M., Buchanan, J., Luik, R. M., and Lewis, R. S. (2006). Ca2+ store depletion causes STIM1 to accumulate in ER regions closely associated with the plasma membrane. J. Cell Biol. 174, 803-813. doi: 10.1083/jcb.2006 04014

Wu, X., Eder, P., Chang, B., and Molkentin, J. D. (2010). TRPC channels are necessary mediators of pathologic cardiac hypertrophy. Proc. Natl. Acad. Sci. U.S.A. 107, 7000-7005. doi: 10.1073/pnas.1001825107

Yonetoku, Y., Kubota, H., Miyazaki, Y., Okamoto, Y., Funatsu, M. Yoshimura-Ishikawa, N., et al. (2008). Novel potent and selective Ca2+ release-activated $\mathrm{Ca} 2+$ (CRAC) channel inhibitors. Part 3: synthesis and CRAC channel inhibitory activity of 4'-[(trifluoromethyl)pyrazol-1yl]carboxanilides. Bioorg. Med. Chem. 16, 9457-9466. doi: 10.1016/j.bmc.2008. 09.047 
Zhang, S. L., Yeromin, A. V., Zhang, X. H., Yu, Y., Safrina, O., Penna, A., et al. (2006). Genome-wide RNAi screen of $\mathrm{Ca}(2+)$ influx identifies genes that regulate $\mathrm{Ca}(2+)$ release-activated $\mathrm{Ca}(2+)$ channel activity. Proc. Natl. Acad. Sci. U.S.A. 103, 9357-9362. doi: 10.1073/pnas.0603161103

Zhang, S. L., Yu, Y., Roos, J., Kozak, J. A., Deerinck, T. J., Ellisman, M. H., et al. (2005). STIM1 is a Ca2+ sensor that activates CRAC channels and migrates from the $\mathrm{Ca} 2+$ store to the plasma membrane. Nature 437, 902-905. doi: 10.1038/nature04147

Zhou, Y., Meraner, P., Kwon, H. T., Machnes, D., Oh-hora, M., Zimmer, J., et al. (2010). STIM1 gates the store-operated calcium channel ORAI1 in vitro. Nat. Struct. Mol. Biol. 17, 112-116. doi: 10.1038/nsmb.1724

Zhou, Y. Y., Wang, S. Q., Zhu, W. Z., Chruscinski, A., Kobilka, B. K., Ziman, B., et al. (2000). Culture and adenoviral infection of adult mouse cardiac myocytes: methods for cellular genetic physiology. Am. J. Physiol. Heart Circ. Physiol. 279, H429-H436.

Conflict of Interest Statement: The authors declare that the research was conducted in the absence of any commercial or financial relationships that could be construed as a potential conflict of interest.

Copyright (c) $2015 \mathrm{Liu}, \mathrm{Xin}$, Benson, Allen and Ju. This is an open-access article distributed under the terms of the Creative Commons Attribution License (CC BY).

The use, distribution or reproduction in other forums is permitted, provided the original author(s) or licensor are credited and that the original publication in this journal is cited, in accordance with accepted academic practice. No use, distribution or reproduction is permitted which does not comply with these terms. 